\title{
Sem mágicas soluções: a prevenção e 0 cuidado em HIVI AIDS e o processo de emancipação psicossocial
}

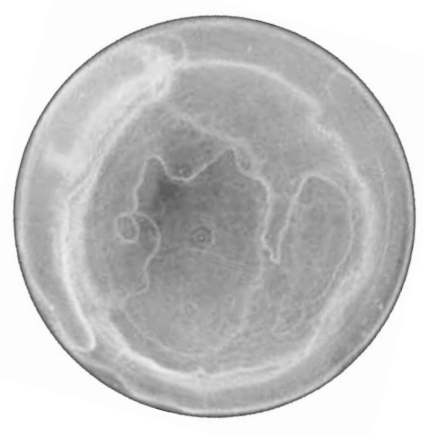

Vera Paiva 1

PAIVA, V. Beyond magical solutions: prevention of HIV and Aids and the process of "psychosocial emancipation", Interface - Comunic, Saúde, Educ, v.6, n.11, p.25-38, 2002.

This text discusses the need to politicize psycho-educational arenas and presents the idea of a "psycho-social emancipation" as one of the references for improved operationalization of the notion of vulnerability in the field of prevention of new HIV infections and of the organization of care for those who are AIDs carriers. Reflecting on actions designed to encourage patients to take their medication and use condoms, it suggests that the prevention of HIV should overcome models devised for "HIV negative" people and that the prevent-assist continuum should be radicalized. To this end, it is pressing to: take into account the facts accumulated in the field of cultural analyses and of psychosocial research in the planning and organization of preventive actions and of providing assistance to HIV carriers, including, for instance, the ideas of oppressive social construction of two genders, masculine and feminine; overcome the notion of "individuals as consumers" (of services, educational programs, condoms and prescribed medication, of behaviors and safe practices to be practiced); foster the innovation of prevention and care actions. Working with the idea of a "subject-citizen individual", co-participant in the psycho-educational arenas whose horizon consists of psychosocial emancipation, can enhance the quality of preventive actions and of integrated care of HIV and AIDS patients, so as to include "all" Brazilians, according to the socio-cultural context of "each one", both men and women, testing positive or negative.

KEY WORDS: HIV, Acquired immunodeficiency syndrome; social support; health education.

Este texto discute a necessidade de politizar os espaços psicoeducativos e propõe a noção de "emancipação psicossocial" como uma das referências para aprofundar a operacionalização da noção de vulnerabilidade no campo da prevenção de novas infecções pelo HIV e da organização do cuidado dos portadores. Refletindo sobre ações para a adesão aos medicamentos e ao preservativo, sugere que a prevenção ao HIV deve superar modelos pensados para cidadãos "HIV negativos" e que se radicalize o continuum prevenir-assistir. Para tanto, é urgente: considerar os fatos acumulados no campo da análise cultural e da pesquisa psicossocial no planejamento $e$ organização de ações de prevenção e de assistência aos portadores, incorporando, por exemplo, as noções da construção social opressiva de dois gêneros, masculino e feminino; superar a noção de "indivíduo-consumidor" (de serviços, programas educativos, preservativos e medicação receitados, de comportamentos e práticas seguras a serem treinadas); estimular a renovação das ações de prevenção e cuidado. Trabalhar com a noção de "indivíduo sujeito-cidadão", co-participante de espaços psico-educativos que têm como horizonte a emancipação psicossocial, pode aumentar a qualidade das ações de prevenção e cuidado integral em HIV e AIDS, incluindo "todos" os brasileiros segundo o contexto sócio-cultural de "cada um", homens e mulheres, positivos ou negativos.

PALAVRAS-CHAVE: HIV; Síndrome de imunodeficiência adquirida; apoio social; educação em saúde.

${ }_{1}^{1}$ Professora do Instituto de Psicologia, Universidade de São Paulo, Núcleo de Estudos para Prevenção da Aids, NEPAIDS/USP. $<$ veroca@usp.br> 
Pensando nos esforços dos últimos anos no campo da prevenção de novas infecções pelo HIV e da organização do cuidado dos portadores, este texto quer discutir a necessidade de politizar os espaços psico-educativos e propor a noção de "emancipação psicossocial" como uma das referências para aprofundar a operacionalização da noção de vulnerabilidade. Trata-se de uma reflexão a partir de nossa experiência em várias pesquisas no Núcleo de Estudos para a Prevenção da AIDS/USP, e do resultado dos projetos em colaboração com programas de Aids e profissionais de saúde ou ainda com ativistas atuando tanto na prevenção quanto na assistência em São Paulo.

Este artigo quer também contribuir para uma reflexão crítica sobre o celebrado programa brasileiro de DST/AIDS, sobre os caminhos construídos por suas lideranças, marcados pela história brasileira de resistência democrática, por profissionais de saúde e ativistas que compartilhavam as mesmas referências em defesa dos direitos humanos, da saúde pública gratuita e universal, $e$ do compromisso com a emancipação e a construção da cidadania. Nem sempre se conseguiu operacionalizar em todos os níveis e radicalmente estas referências, ou entender exatamente como avançamos (ou não) sem perdê-las de vista. Essa opção, de qualquer maneira, traduzida nas iniciativas não-governamentais $e$ programas governamentais, sempre colocou o desafio de articular prevenção do HIV, entre os grupos mais vulneráveis, e a assistência aos portadores, assim como a proteção de seus direitos. Mais do que de intervenções espetaculares $e$ magicamente definitivas com que sonhávamos nas urgências da primeira década, as ações de prevenção das infecções sexualmente transmissíveis e do adoecimento dependeram de um longo processo de aprendizado individual e coletivo de como lidar com as dificuldades materiais, sócio-culturais, políticas e subjetivas que se atualizam cotidiana e dinamicamente.

Aprendemos que conseguir consistência e perseverança na direção de dois indicadores clássicos de sucesso - a prática consistente do sexo seguro e a adesão à medicação ou aos serviços de saúde - na maioria das vezes implicam um desafio permanente, dia após dia, de situação em situação, tanto do ponto de vista dos indivíduos como dos serviços que buscam apoiá-los. Trata-se de um processo que tem sido mais lento do que gostaríamos ou precisaríamos, embora tenha dependido de momentos de salto de qualidade e especiais. É resultado, por exemplo, de uma campanha de mídia bem desenvolvida, ou da tensão e do brilho na aliança dinâmica entre profissionais de saúde, programas e ONGs, que se movimenta entre a cooperação e cooptação, o embate e o apoio mútuo, com momentos de grande visibilidade nas ações políticas de uma parte ou em conjunto. O processo tem se beneficiado da lenta aprendizagem nos espaços psicoeducativos, do impacto nos grupos ou comunidades, das iniciativas de "oficinas de sexo seguro" ou, mais recentemente, da organização de sessões interativas dos "grupos de adesão à medicação" em serviços de referência para portadores e em organizações não governamentais. Estes espaços menores e de aprendizagem conjunta provocam os insights que facilitam a adesão de cada paciente à medicação ou à camisinha $e$, ao mesmo tempo, ajudam profissionais a reconhecer os fatos, em geral psicossociais, que facilitam ou dificultam a prevenção.

O que reconhecemos como sucesso dos últimos anos de respostas à expansão do HIV/AIDS no Brasil dependeu de vários destes elementos, tornando a reflexão pausada sobre esse processo uma tarefa árdua, já que não há nenhum instrumento seguro que consiga dar conta de tão complexa sinergia em 
movimento. Sem abrir mão dos avanços, a crítica deve se aprofundar para enfrentarmos tanto os novos desafios como os velhos dilemas que permanecem à sombra do que, no momento, parece bem sucedido.

\section{O continuum entre prevenção e assistência aprofunda operacionalização da noção de vulnerabilidade.}

O fato de que prevenir e assistir são duas faces de um mesmo desafio estava no horizonte das primeiras respostas organizadas ainda na primeira década da epidemia no Brasil (Teixeira, 1997). Observando a partir do plano mais estrutural e programático, as iniciativas que têm beneficiado os que têm Aids com acesso ao tratamento de qualidade sempre tiveram um impacto definitivo na prevenção de futuras infecções. Por exemplo, só quando se reconheceu publicamente que as pessoas que adoeciam de aids não deveriam perder seus direitos como cidadãos, quando se escutou os ativistas organizados se recusando à "morte civil" e colocando o foco na solidariedade (Parker, 1994), organizou-se seu acolhimento nos serviços de saúde ao mesmo tempo em que a prevenção do HIV passou a ser entendida como direito de todo brasileiro, estendida a todo cidadão. Observando a partir do plano individual e subjetivo, assim se construiu um sentido positivo de se fazer o teste anti-HIV, porque se teria acesso ao tratamento e à vida com qualidade. Se olharmos o plano da ação política, a partir da iniciativa dos ativistas que reivindicaram nos tribunais o acesso ao tratamento, fortaleceu-se a decisão dos profissionais responsáveis pelas políticas públicas de saúde pela distribuição universal do AZT com recursos do orçamento nacional. Portadores e grupos mais vulneráveis foram estimulados a sair do isolamento e a buscar serviços de Aids, organizaram-se os centros de testagem anônima, o acolhimento e o aconselhamento no sistema de saúde. Além de beneficiar os diretamente atingidos, afinou-se a vigilância epidemiológica, fortaleceu-se a rede laboratorial e de distribuição de medicamentos para, em seguida, criar o desafio de sustentar em longo prazo essa política, que às agências internacionais parecia um sonho impossível. A ousadia foi não recuar diante das pressões no processo para o acordo com o Banco Mundial, que só permitia uso de seu empréstimo para as ações educativas já que, como país de "terceiro mundo", nos caberia apenas centrar esforços na prevenção de novas infecções. Esse processo, buscando emancipação psicossocial e cidadania, tem sido fundamental para garantir acesso sustentado a bons serviços, garantir respeito a direitos e à ética e, ao mesmo tempo, alimentar a constituição de sujeitos e identidades cidadãs. Desaguou no comprometimento do orçamento nacional, na produção de genéricos e na ação política internacional, governamental e não-governamental, que tem confrontado laboratórios e leis de patentes.

Neste caminho, foi fundamental a legitimidade crescente da noção de vulnerabilidade (individual e coletiva) como alternativa às noções de "grupo de risco" e de "práticas de risco" (Ayres et al., 2000; Paiva, 2000a). Dinâmico, o esforço para sustentar a política de acesso universal à medicação anti-HIV permitiu, em seguida, que acumulássemos mais evidências sobre os contextos psicossociais (ao mesmo tempo sócio-culturais e subjetivos, individuais $e$ coletivos) que aumentam ou diminuem a vulnerabilidade das pessoas ao HIV $e$ ao adoecimento. Queremos sugerir para o debate que a adoção desta perspectiva deve ser radicalizada e a reflexão sobre sua operacionalização nas 
ações de assistência e prevenção aprofundada. Usando como exemplo a prevenção da transmissão sexual do HIV e a atenção à saúde sexual $e$ reprodutiva dos portadores, discutiremos algumas das noções que têm informado a prevenção primária e secundária que merecem reflexão à luz deste "caminho brasileiro" e de suas referências.

\section{A prevenção segue pensada para cidadãos "HIV negativos"}

Programas governamentais e não-governamentais têm se dedicado corretamente a promover políticas não discriminatórias, defendendo os direitos dos portadores, ampliando a consciência de que a Aids atinge igualmente a todos. A sexualidade a ser abordada é a de "todos", como se "todos" fôssemos igualados pelas mesmas práticas, sem considerar que práticas sexuais sem seus sentidos particulares em cada cena sexual, em cada contexto sócio-cultural, não existem (Paiva, 2000b). A conseqüência simplificadora desta concepção é o fato

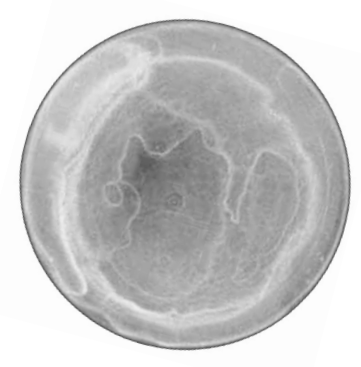
de que programas e pesquisas, intervenções na mídia ou em pequenos grupos face a face, traduzem sempre seu público alvo como o indivíduo "soronegativo", sinônimo de "todos", que deve se proteger de alguém potencialmente "soro-positivo". Discutem-se os obstáculos que impedem o "negativo" de aceitar ou considerar que outras/outros possam ser "HIV positivos". Mas as dificuldades de o portador fazer o teste ou reconstruir-se para uma nova vida, protegendo os outros ou a si mesmo de re-infecção nunca são discutidas abertamente, como se pertencessem a uma outra nação. Os direitos reprodutivos dos portadores permanecem marcados pelo silêncio ou restritos às controvérsias de corredores e não têm sido debatidos mais sistematicamente nos programas de Aids, ratificando sua morte civil (Santos et al., 1998).

$\mathrm{Na}$ literatura disponível, os poucos estudos encontrados sobre a sexualidade das pessoas vivendo com HIV confirmam que os determinantes sócio-culturais da sexualidade e vida reprodutiva, inclusive do sexo não-protegido, são os mesmos entre os portadores e não-portadores (Schiltz \& Sandforth, 2000). No debate sobre a dinâmica da transmissão sexual do HIV permanece com vida longa a descrição de condutas sexuais ainda acusadas de "promíscuas", ou sob suspeita, numa visão mais conservadora, e a vida afetivo-sexual dos portadores segue desconsiderada ou reprimida (punida?) quando a pessoa chega a um serviço de saúde ao se descobrir portador. Nos centros de referência, encontramos profissionais que espelham valores e significados para o sexo $e$ para a Aids em que foram socializados, em geral conservadores, estigmatizadores daqueles com opções diferentes da sua. Encontramos, também, profissionais que se identificam com valores mais abertos à diversidade, mas que muitas vezes tratam a conduta sexual como irresponsavelmente culpada porque "não usou a camisinha", como se fazer sexo seguro dependesse sempre da vontade e da razão informada, acusando os que não absorvem adequadamente ("desconsideram") os guias para a proteção do sexo (Paiva et al., 2001).

O aconselhamento pós-teste, obrigatório, é um dos poucos momentos em que se discute a sexualidade dos portadores, mas o acesso ao aconselhamento não tem crescido. $\mathrm{O}$ foco deste aconselhamento tem sido falar da necessidade de usar o preservativo, no máximo "demonstrar" como se usa essa "receita de comportamento", sem considerar outras dimensões da sexualidade do portador ou sequer pensar sobre suas intenções reprodutivas (Enhancing Care Initiative, 
2001). Problemas conhecidos dos que trabalham com a prevenção permanecem: numa sociedade que não estimula a comunicação franca sobre as conseqüencias do sexo, embora seja "sexo-estimulante" a qualquer hora do dia nos meios de comunicação, como ajudar as pessoas a comunicar a seus parceiros sua situação de portadores? Como incluir na motivação para o uso do preservativo a necessidade de se proteger (e ao parceiro) da re-infecção? Como lidar com os efeitos psicológicos negativos do diagnóstico na vida sexual, como a depressão e o isolamento freqüentes? Como lidar com o medo da violência conseqüente ao estigma que ainda marca a vida dos portadores, mesmo estigma com que os "negativos" não querem se identificar $e$ psicodinamicamente acaba por dissolver a consciência de sua provável vulnerabilidade?

Se tomarmos como exemplo os estudos sobre a sexualidade de pessoas vivendo com HIV apresentados na XIII Conferência Internacional de AIDS na África do Sul (International Aids Conference, 2000), encontramos investigações realizadas em vários contextos psicossociais: homens norte americanos, trabalhadores imigrantes na Ásia, jovens vivendo com HIV, mulheres em clínicas de pré-natal na África, trabalhadoras do sexo, lésbicas na Califórnia, e usuários de drogas no Rio de Janeiro e em Sacramento. Como a sexualidade é uma dimensão da vida que sabemos ser profundamente determinada pelo contexto sócio-cultural em que acontece, é importante perceber o que as vivências dos portadores e comunidades mais vulneráveis têm em comum e ao mesmo tempo o que é específico de cada grupo, indivíduo ou de seu momento na vida. A diversidade é um problema para quem pretende generalização das sugestões programáticas para qualquer contexto.

Seria inovador abandonar a tentação de encontrar uma tecnologia universal, "a mais eficaz", para algo que reconhecemos depender de cada contexto social e intersubjetivo. Apesar disto, temos ainda centrado as ações de prevenção ou aconselhamento sem compartilhar com os pacientes ou educandos o que sabemos sobre os vários contextos sócio-culturais, sem valorizar a diversidade. A informação de que precisamos adaptar os guias para o sexo mais seguro à vida de "todos" nós, na verdade deveria significar adaptar à vida de "cada um", nem sempre é compartilhada como informação relevante para que as pessoas se previnam ou se cuidem. Tem sido difícil, portanto, abandonar a referência

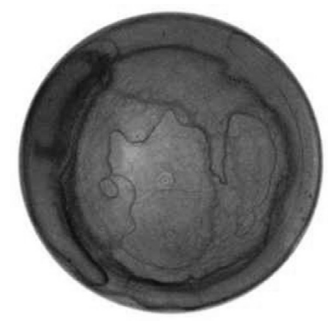
centrada nas "práticas de risco, comportamentos de risco", nas "falhas" prováveis na adesão, pré-definidas pelo receituário. No máximo fazemos "materiais diferentes" que fazem o marketing da mesma idéia (Use camisinha! Previna-se!) mais adaptado ao gosto e linguagem do "público alvo em questão" (mulheres ou homens, "heteros" ou "homos", jovens, trabalhadores do sexo etc). Os "positivos" seguem presença quase inexistente como "alvo" desta produção.

No Brasil, estudos realizados entre mulheres portadoras (Enhancing Care Initiative, 2001; Santos et al., 1998; Paiva et al., 2001) confirmaram que o portador passa por um processo de adaptação ao diagnóstico, de várias fases e diversas maneiras de lidar com a vida e com sexualidade, que vão variando no tempo. Uma adaptação semelhante ao que se descreve na literatura sobre o processo de assumir para si e para o mundo o desejo homoerótico (RotherdamBorus \& Miller, 1998). Muitas portadoras, depois do resultado do teste, abrem mão de sua vida sexual, às vezes definitivamente, com medo de infectar ou então serem abandonadas por futuros parceiros, com dificuldades de se 
comunicar sobre sexo e sobre o diagnóstico. A maneira de lidar com a sexualidade dependerá da qualidade do apoio que os portadores recebem nesse processo, e o momento do diagnóstico é crucial. Independente da primeira reação, a maioria das portadoras, principalmente as mais jovens, mantém ou retoma a vida afetiva e sexual, assim como suas intenções de maternidade (ou paternidade); esta a dimensão que encontra mais obstáculos para ser acolhida. Como em todas as comunidades e grupos afetados pela Aids, mesmo nas mais carentes e vulneráveis, a adesão e o sexo mais seguro têm sido possíveis $e$ acontecem também entre as portadoras. No caso do preservativo, as portadoras usam-no consistentemente numa proporção três vezes maior que entre as mulheres brasileiras em geral (CEBRAP \& Ministério da Saúde, 1999), mas um terço das mulheres portadoras que são ativas sexualmente continuam sem usar preservativo (Enhancing Care Initiative, 2001). Os programas podem, portanto, fazer diferença, mesmo quando não transformam radicalmente as condições materiais, estruturais ou as mentalidades que aumentam a vulnerabilidade ao HIV e ao adoecimento das mulheres brasileiras.

Neste momento da história da resposta em busca do controle do HIV/AIDS, um dos novos desafios que podem nos ajudar a inspirar a renovação das práticas e a sensibilizar programas e profissionais para uma nação de cidadãos positivos e negativos, aprofundando o continuum entre prevenção $e$ assistência, é entender melhor o impacto dos sucessos da terapia anti-retroviral nas mudanças da vida, também amorosa e sexual, dos portadores e também como os vários grupos e pessoas pensam a prevenção.

\section{Gêneros, no plural}

Tanto nas experiências mais interessantes de prevenção, como nos centros especializados em atendimento aos portadores do HIV, raramente se tem incorporado a compreensão que já acumulamos na análise dos aspectos sócioculturais que ampliam a vulnerabilidade ao HIV e ao adoecimento. Os serviços continuam basicamente organizados para dar conta dos fatos biomédicos e da educação centrada nas vias de transmissão e na promoção dos instrumentos de proteção (preservativos, abstinência, seringas descartáveis etc), ou no controle clínico da infecção e da adesão.

A dimensão das relações de gênero e do respeito à diversidade nas várias opções sexuais tem sido incorporada em muitas ações de prevenção, mas gênero ainda continua sendo pensado no singular, no feminino, como sinônimo de opressão feminina; não se aprofunda, nas ações de prevenção, o lidar com o impacto das relações de gênero no aumento da vulnerabilidade dos homens. Ao mesmo tempo, as necessidades das mulheres portadoras diante de sua responsabilidade maior pela família e filhos não têm sido efetivamente consideradas na organização de seu cuidado; seu acesso ao atendimento ginecológico é muito menor do que deveria, pais e mães não têm lugar para deixar os filhos enquanto são atendidos (Tunala et al., 2000). Onde se discute os fatos da transmissão materno-infantil, a possibilidade de reprodução assistida com os casais (homens e mulheres portadoras), ou direitos reprodutivos do homem e da mulher portadora do HIV, ou os desafios da conjugalidade homoerótica?

No caso da prevenção do HIV, foi no trabalho com jovens que essa dimensão de dois gêneros foi incorporada na história da epidemia. O fato recente das 
crianças portadoras amadurecerem como jovens sexuados talvez ilumine esse buraco negro na ponta do cuidado ao portador. O silêncio, ou a ambigüidade diante da sexualidade do portador, em especial sobre as intenções reprodutivas das pessoas vivendo com o HIV, somado ao pouco conhecimento sobre os métodos de contracepção mais apropriados ou sobre direitos reprodutivos a que estas têm tido acesso, tem sido descrito como um dos mais difíceis obstáculos a superar (Enhancing Care Initiative, 2001).

Teremos que, criativamente, continuar buscando a "des-naturalização" das "bíblicas" definições sobre os gêneros, que mantém os programas de infecções sexualmente transmissíveis desarticulados dos programas de saúde da mulher, os homens desassistidos para lidar com seus dilemas reprodutivos (quase invisíveis nos programas de saúde da mulher), e programas de saúde que raramente permitem às "esposas e mães" serem incentivadas a fazer o teste anti-HIV nos serviços de ginecologia e pré-natal (um espaço de "todos", onde não se pode pensar em HIV), e os portadores sem espaço para pensar suas intenções reprodutivas (um espaço que não é de "todos", do "todo" das pessoas vivendo com Aids, mas tem focalizado a sua "parte portadora").

Tais temas emergem sempre como uma das demandas mais importantes nos grupos de apoio para mulheres portadoras, que se somam às dificuldades de sobreviver com falta de dinheiro, emprego e sofrendo discriminação (Tunala et al., 2000; Paiva et al., 1998).

\section{Do consumidor ao sujeito-cidadão}

Os fatos conhecidos sobre o impacto da estrutura sócio-econômica e da exclusão, da pobreza e da raça, que afetam indivíduos imersos numa sociedade desigual como a nossa (Parker, 2000), estão ausentes do conjunto de conhecimentos valorizados nos treinamentos de profissionais, nas informações priorizadas como centrais nos programas de prevenção e aconselhamento.

Estes fatos são menos considerados na análise de como estão organizados esses serviços de atenção aos portadores do que poderiam, deixando de iluminar o caminho para possíveis inovações.

Sabemos que consensos sobre como medicar os pacientes, rapidamente passados numa atitude "receitadora", que modelos prontos de como se comportar, ou o marketing de preservativos pagos com dinheiro público (e não pela indústria que lucra com eles) não têm sido suficientes para produzir as mudanças que ainda precisamos (Baptistella Nemes, 2000; Teixeira et al., 2000). Para superar a visão de clientes consumidores de serviços e produtos (medicação ou preservativos) e incorporar a visão de sujeitos da adesão (ao preservativo ou à medicação) precisamos entender que o consumidor é apenas uma das faces do cidadão.

A história das respostas que temos dado à epidemia e das idéias em disputa na era da globalização nos mantém ambíguos sobre como definir o indivíduo participante das ações de prevenção e cuidado. Indivíduo aqui definido simplesmente como "a pessoa humana considerada quanto a suas características particulares, físicas ou psíquicas" (Aurélio). Embora se fale muitas vezes em promover "sujeitos e cidadania", atua-se como se o cidadão fosse sinônimo do consumidor.

O indivíduo pensado como consumidor é sujeito do direito de escolher e consumir o que existe formatado em outro lugar por algum produtor. 
Produtor de idéias e valores disseminados pela mídia, por instituições religiosas, educacionais, por serviços de saúde. Consumidor de serviços $e$ produtos. Um indivíduo que tem direitos de consumidor e quer virar sujeito do consumo passa a ser objeto de uma "educação bancária" (Freire, 1989), na qual um conjunto de informações definidas como relevantes pelo educador (produtor) são "depositadas" naquele que deve consumi-la. Ou é um cliente de oficinas e grupos de apoio organizados para "modelar" novos comportamentos e rever práticas definidas a priori como pouco saudáveis. O consumidor deve aprender a usar adequadamente os produtos (preservativos, scripts de sexo seguro, medicação) e conseguir realizar os comportamentos que devem ser treinados. O pressuposto, mesmo que inconsciente, é de que o produtor sabe o que é mais adequado e aceitável para "todos", e age com a pressa e boa intenção de quem não quer correr o risco (público) de que o consumidor não realize o que se espera dele. E escolhe o meio (que funciona como "mídia", "estratégia de marketing") que trata de vender essa idéia, produto ou comportamento.

Consumidor é o paciente objeto da manipulação clínica que pretende olhar o portador apenas como portador, ou seja, vai tratá-lo pela parte, numa organização do atendimento que abre espaço apenas para entregar ou avaliar o efeito da receita do remédio para tratar da infecção, garantindo que "todos" entendam as tomadas, como nos manuais de uso dos demais produtos distribuídos no mercado. É um indivíduo portador de alguma deficiência - falha imunológica, de informação, de habilidades - que deve ser tratada, suprida, treinada.

Quantas vezes temos chamado as ações de prevenção primária e secundária que iniciamos de "intervenção"? O dicionário Aurélio a define como "ato de intervir, meter-se de permeio, vir ou colocar-se entre, ingerir-se, interpor sua autoridade..."

Quem não pode ou não consegue ter acesso ao consumo dos produtos, não consegue ter acesso aos serviços, não consegue realizar as propostas, ou não quer consumi-las, fica fora, não participa da interação, do debate, não tem acesso ao aconselhamento, à oficina. Ou se sente fatalisticamente impedido, na maioria das vezes acusado e culpado. Nesta perspectiva, desigualdade vira exclusão, naturalizada, e os defensores radicais desta concepção de indivíduo naturalizam e essencializam a exclusão: "sempre existiram e existirão excluídos".

Quem trabalha com uma outra idéia de indivíduo, o sujeito-cidadão, encara sua proposta como ponto inicial para uma vívida interação e não um produto acabado. Uma proposta a ser negociada, adaptada, comunicada e não imposta ou ordenada. Espera-se que o indivíduo-cidadão se relacione, seguindo um movimento de desconstrução e reconstrução, de apropriação coletiva $e$ individual de propostas. Propostas de governos, líderes comunitários, acadêmicos, mídia, provedores de serviços, propostas de prevenção. Sente-se "no direito de ter direitos e de criar direitos" ${ }^{2}$. O indivíduo-cidadão compartilha direitos e responsabilidades como alguém que se pensa como parte de um contexto maior, sobre o qual exerce influência, colocando-se como agente e sujeito de suas ações. É estimulado a progredir, melhorar sua qualidade de vida, ao mesmo tempo em que se pensa como parte de uma comunidade mais ampla (nação brasileira, grupos de afetados pela Aids, pobres, negros, os de mesma opção sexual). Nesta perspectiva, lida-se com a
${ }^{2}$ AYRES, J.R.

Comunicação

Pessoal, Reunião da Equipe ECI/BRASIL

- São Paulo. jun. 2000. 




${ }^{3}$ Em inglês, o termo adherence tem sido usado na maioria dos artigos sobre adesão ao tratamento como sinônimo de compliance, embora alguns autores façam distinção entre os dois termos que é interessante para esta discussão. Adherence reflete uma atitude do indivíduo em face da medicação prescrita, isto é, o indivíduo segue a prescrição porque o deseja, enquanto compliance reflete uma atitude de consentimento em relação ao médico para tomar a medicação. Adherence representa o fato de um indivíduo seguir uma determinada prescrição, enquanto

"compliance" é uma avaliação disso (Teixeira et al., 2000). desigualdade sempre pensando em ampliar os beneficiários, em como incluir. A desigualdade não é natural, é socialmente construída e pode ser desconstruída e superada, coletivamente.

Podemos, certamente, pensar em superar o impacto da desigualdade e da exclusão enraizados numa idéia de indivíduo ou noutra. O formato das ações, as maneiras como nos relacionamos com as pessoas e situações de interação serão, contudo, radicalmente diferentes, tanto nas ações nos níveis mais estruturais ou programáticos como nos espaços face a face que querem apoiar os indivíduos em suas escolhas da vida cotidiana.

Do ponto de vista do indivíduo-consumidor, os direitos de trabalhadores, de homens ou mulheres, direitos sociais e econômicos, de fé ou culturais, caem num buraco negro da conquista individual, de empoderamento sobre o outro, empoderamento pensado como compensação "hidráulica", da auto-estima percebida como resultado da vontade individual, vontade que permanece inconsciente da dependência do contexto coletivo: Use camisinha! Tome a medicação corretamente! Acredite que vai conseguir! Seja eficaz! Aumente a sua auto-estima! (Paiva, 1996). Desejos são transformados em objetivos de consumo ou direitos do consumidor que reclama do engodo da mercadoria, mas não pode se propor a inventar "o inédito viável", como diria Paulo Freire (1989). Para os pobres e excluídos sobra o best attainable care (a saúde "possível" para pobres), restam os direitos à saúde e educação com a qualidade "possível". Sobra a prevenção porque proíbem os países em desenvolvimento de sonhar com o tratamento - aquele que é acessível, entretanto, às elites de qualquer país, que são muito mais solidárias entre si do que com seus conterrâneos, num mundo em que uma determinada forma de globalização tem hegemonia, da África às Américas.

Do ponto de vista do indivíduo-cidadão, estaremos pensando na "educação libertadora", conscientizadora e emancipadora, politizada, na "adesão" (adeherence e não compliance) ${ }^{3}$, na solidariedade social, no atendimento centrado nas equipes multidisciplinares e não no clínico, nos grupos face a face e comunitários mais politizados. Estaremos sempre inventando movimentos sociais que transformem mentalidades, contra a discriminação e o sexismo, pela afirmação positiva que celebra a diversidade, a comunicação, a ação solidária, que desnaturalizem a injustiça e a desigualdade ou iniqüidade. Iniciativas que afirmem identidades políticas positivas que consigam se comunicar e fazer alianças, e, como no caso recente da discussão sobre patentes liderada pelo Brasil, até disputem espaço no cenário internacional para uma visão de saúde coletiva, pública e decente para todos.

As iniciativas no campo da Aids que ousaram "criar direitos", por exemplo, obrigando o governo a fornecer medicação, estimularam as mais recentes respostas de servidores em laboratórios públicos que organizaram a capacidade para produzir a medicação anti-HIV e em seguida, somaram no movimento social que depois colocou o governo negociando quebra das patentes ou dos preços internacionais (Passarelli, 2001). Com a resposta construída durante anos, criaram-se ilhas de cidadania que dependeram da progressiva organização dos afetados e da resposta nos programas nacionais e estaduais de DST/AIDS. Os programas de Aids são uma exceção no país, mas demonstram que saúde pública de melhor qualidade é possível.

O desafio de sustentar e ampliar para mais gente e para outras áreas da saúde o sonho realizado é um estímulo e desafio para a criatividade cidadã, 
dificilmente ocorreria à mentalidade consumidora. O consumo sem independência ou questionamento de ordens injustas, manterá a exclusão naturalizada, ou as dificuldades do processo alienadas do contexto em que se dão: ordenadas por uma desigualdade de sexos e gêneros, de etnias $e$ diferenças de fé, ordenadas por uma visão adultocêntrica ou marcadas por um olhar de classe.

\section{Politizar os grupos psico-educativos e os grupos de apoio}

Espalhadas em várias regiões do planeta, várias experiências têm desafiado o contexto sócio-cultural, o contexto psicossocial em que vivem as pessoas mais vulneráveis ao HIV, formando multiplicadores para discutir as normas culturais para os gêneros (Unaids, 1999), aumentando a consciência da vulnerabilidade social, e capacitando-os para serem agentes de sua própria saúde, aumentando sua habilidade de comunicação com parceiros ou de reivindicação por serviços de saúde. Os estudos sistemáticos dos programas educativos, especialmente os conduzidos entre jovens (Unaids, 1997), têm enfatizado que os programas que usam uma linguagem simples e ensinam as pessoas a se proteger de fato, mostrando passo a passo como se usa um preservativo e outras formas de proteção, como carregar uma camisinha na bolsa, comunicar-se com o parceiro ou no balcão da farmácia, como contar com o apoio da família e do grupo de pares, são os que garantem melhores resultados. Abordagens semelhantes e bem sucedidas são encontradas em várias experiências que buscam promover a adesão à medicação (Teixeira et al., 2000).

Essas iniciativas dependem bastante de atividades em pequenos grupos, chamados convencionalmente de "oficinas" (workshops), em geral uma proposta de educação dialógica. Os ativistas das oficinas, inclusive das primeiras e inovadoras respostas das comunidades gays, organizadas em São Francisco e Nova Iorque e que idealizaram as primeiras "oficinas de sexo seguro", reconhecem sua inspiração na tradição inaugurada por Paulo Freire, de educação como prática da liberdade. Essa "pedagogia do oprimido", cunhada originalmente nos anos sessenta, participa até hoje em várias partes do mundo como tarefa-auxiliar dos movimentos sociais contra a pobreza e outras formas de exclusão social. Nessa tradição, ter acesso à educação é em si mesmo um passo crucial, mas apenas quando a linguagem popular (palavras e sintaxe) e os temas relevantes da vida dos oprimidos são valorizados. Só têm sentido e eficácia as ações educativas que conseguirem quebrar o silêncio e a invisibilidade social dos que, hoje, chamamos de excluídos.

A partir da metade dos anos 1980, também na América Latina, quando se iniciou o processo de democratização, outras definições de opressão, além da pobreza, foram incluídas no cenário de iniciativas comunitárias e nãogovernamentais. Os sexos, o gênero (ainda no singular e no feminino) e a raça (negra) entraram no cenário político, principalmente pela via da política de identidade e de sua afirmação positiva: "mulheres" ou "feministas", "homossexuais" ou "GLS/GLT", "pretos", ou "portadores do HIV" (e não "aidéticos"). Uma nova face da pedagogia libertadora surgiu com as "oficinas", "grupos de apoio", "grupos de vivência" etc. São espaços cujo objetivo é compartilhar experiências íntimas das dificuldades de viver

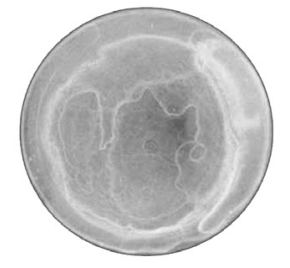


aquela parte que se sente estigmatizada, excluída, e falam principalmente da opressão enraizada no corpo diferente ou menos poderoso (o feminino, o corpo jovem, os corpos não-brancos, os que expressam desejos diferentes, corpos doentes, deficientes). Organiza processos vividos em grupo para desconstruir velhos estigmas e reconstruir coletivamente identidades positivas. Muitos desses processos coletivos criaram iniciativas de luta contra a discriminação.

Esta experiência foi incorporada em propostas de prevenção e assistência. Em outros textos temos chamado esse tipo de experiência, face a face e em grupos, de "grupos psico-educativos", porque além da pedagogia desenvolvida para a educação libertária nos movimentos populares, incorporaram técnicas de psicologia de grupo, que vão do psicodrama aos grupos operativos. $\mathrm{Na}$ experiência brasileira, estas propostas que se ampliaram de educativas para psico-educativas foram inspiradas também pela produção latino-americana da "psicoterapia do oprimido", mas marcadas pelas várias experiências norteamericanas resultantes da antipsiquiatria e da bioenergética, entre outras. Essas propostas de "vivências em grupo" geraram uma abordagem mais intersubjetiva que valoriza, por um lado, a noção de diversidade e criatividade pessoais, e por outro, a afirmação de identidades compartilhadas, em busca da emancipação pessoal e coletiva, da cidadania plena.

Essas iniciativas se organizam a partir da decepção com o espaço público que constrói a democracia, virtual ainda para formas de viver a vida que fazem as pessoas se sentirem minorias excluídas, e que mantém sem a possibilidade de exercício dos direitos individuais grupos inteiros de cidadãos que têm opções $e$ valores mais singulares. Estes espaços têm fortalecido o consumo de identidades prontas, e muitos grupos se organizam "glamurizando" identidades positivas e estilos de vida, condutas propostas por sua "vanguarda", também como produtos de consumo. Mas podem radicalizar o isolamento quando permanecem por demais dogmáticos, quase corporativos. Afastam logo seus consumidores decepcionados com o fato de enfrentarem a realidade material e as hegemonias simbólicas "lá fora", fora dos grupos e dos espaços protegidos, na dura vida real, na qual não conseguem realizar a identidade consumida e incorporada rigidamente ou a liberdade de ser diferente.

A decepção com o consumido acaba por afastar o consumidor, empurra-o muitas vezes de volta ao velho fatalismo, ao silêncio ou ao disfarce sofrido. Mais raramente essa decepção tem criativamente se organizado numa ideologia, num conjunto de valores que conseguem se comunicar, proclamar que o que visa um interesse particular é direito, uma obrigação social. Recuperar a origem mais politizada dos grupos psicoeducativos estimularia o despertar do cidadão público adormecido no consumidor privado, aprofundando-os como um momento no processo de emancipação psicossocial.

Politizar significa olhar além do nosso próprio espelho narcísico, recuperar o que nos une como excluídos por aquela parte que nos difere de "todos", expandir uma identidade política defensiva para nos juntarmos a "toda a gente", porque todos temos direito à liberdade de ser e sonhar. Politizar implica reconhecer que há muitos outros excluídos, diminuir a frustração individual com os limites impostos pelo contexto sócio cultural, superar a culpa de não seguir os guias para ser, culpa inconsciente das condições históricas que produziram maior vulnerabilidade e a exclusão. Dependemos, para a emancipação, de poder fazer história, de fortalecer alianças políticas - que são 
diferentes, como lembra Maria Betânia Ávila", de buscar apoio para "a minha luta". Politizar nos obriga a cultivar mais plasticidade com as soluções definitivas e prontas, porque temos que nos comunicar e negociar. Politizar significa negociar soluções a dois, mais "poder de" e não ter mais poder "sobre" (Paiva, 1996).

Quando esse tipo de espaço psicoeducativo acontece em programas de prevenção do HIV e da Aids, essa abertura à politização valoriza a sabedoria produzida na vida vivida que pode ser compartilhada também com os profissionais que coordenam a atividade, incentiva a busca conjunta de outros espaços solidários e soluções fora do escopo dos projetos e programas. Evita a cooptação pela gratidão a um serviço que sabemos ser de qualidade superior aos outros serviços de saúde no Brasil, e garante o controle social sobre a qualidade e a ética do cuidado. Parafraseando Fernando Seffner ${ }^{5}$, que se referia à escola pública em comparação com a privada, essas inovações só podem acontecer nos serviços públicos de saúde, onde a saúde não é ainda um produto de consumo, mas um direito. Nos serviços privados de saúde e educação a lógica é a do consumidor.

Do ponto de vista subjetivo e individual, as ações que promovem também a cidadania e estimulam as pessoas a serem agentes de sua vida integral, sujeitos que escolhem e decidem, adaptam os guias e propostas a sua realidade e são apoiados neste caminho, permitem às pessoas refletirem e modificarem modos de vida, uma atitude ou seu comportamento, conscientes da teia que engendra sua vulnerabilidade. A conscientização do contexto permite a plasticidade de lidar com os obstáculos nos cenários mais vulneráveis, que depende do sujeito atento que constrói para si práticas aceitáveis em sua vida real, ou participa da mobilização de grupos e comunidades buscando diminuir as dificuldades compartilhadas no ambiente social em que vivem. Politizar diante de nós mesmos significa poder reconhecer novas necessidades, dar voz interna a desejos inéditos, realizar novas faces, atualizar personas, potenciais não vividos, virtualidades do vivido nunca antes considerados, reprimidos, estimulados ou emergentes diante de novas situações de vida ou mobilizados por contextos coletivos. É poder negociar e transformar nosso velho eixo de identidade, maleabilizar e mudar velhos papéis. Diante de nós mesmos, politizar é considerar nossas várias faces e necessidades conflitantes, ter plasticidade para realizarmo-nos em cada contexto intersubjetivo, possível somente a partir de uma radical consciência de alteridade, como ipseidade (Ayres, 2001).

Todos podem se adaptar e aderir aos guias e sugestões, para além das receitas prontas, folhetos ou campanhas de mídia, ou da simples obediência às ordens genéricas de autoridades sanitárias. Já se descreveu como a comunicação sobre o uso de medicação anti-HIV não deve ser imperativa, e como a adesão ao coquetel é uma co-construção entre profissionais e pacientes (Paiva et al., 2000c; Baptistella Nemes, 2000). A adesão é um processo de aprendizado individual e coletivo de como lidar com as dificuldades materiais, sociais $e$ individuais de "engolir" a medicação e com a condição de pessoa soropositiva, ou com as dificuldades de fazer sexo seguro nos contextos psicossociais que ampliam a vulnerabilidade. Não se resolve numa única conversa com o médico, por mais bem-intencionado, amigo e receptivo que seja, e ambos devem constantemente adaptar a "tabela" de uso da medicação e a necessidade do uso de camisinha a cada situação de vida, que continua mudando. Não se resolve
${ }^{4}$ Comunicação

pessoal. In: SEMINÁRIO SEXUALIDADE E

POLÍTICA NA AMÉRICA LATINA. 2001. Rio de Janeiro: ABIA, 2001.
${ }^{5}$ Comunicação pessoal. In: SEMINÁRIO PREVENÇÃO À AIDS: LIMITES E POSSIBILIDADES NA TERCEIRA DÉCADA. 2001, Fortaleza: ABIA, 2001.

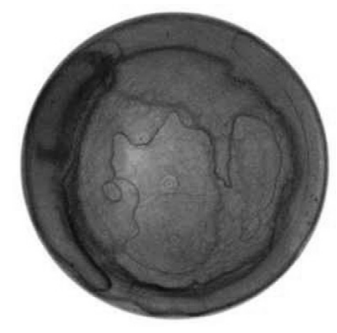


${ }^{6}$ Comunicação pessoal, jun. 2001. numa oficina ou grupo de apoio despolitizado.

Um processo politizado, emancipatório, é sempre mais difícil, porque a arte da política é a arte da negociação, depende de paciência e tempo. Afinal, é impossível "consumir" mudanças prontas. O que pode nos parecer interessante para consumo não transforma a vida que levamos num passe de mágica e só mudamos a partir da realidade viva em que vivemos e não daquela vendida como cenário de produtos prontos para consumo, por mais bem embalados e intencionados.

Não há "intervenção" que mágica e definitivamente proteja, cuide e assista.

Só mudamos a partir do que somos: país desigual, prenhe de violência simbólica e estrutural, instituições pouco democráticas, e uma diversidade de comunidades e pessoas complexas (com seus mil lados buscando realização), mas criativas. Só mudamos a partir do que nossa história pessoal, necessariamente psicossocial, construiu como memória e ipseidade, identidade e alteridade, e também do sonho do que queremos ser e viver.

Para isso precisamos contar com o processo, de atos de amor menos narcísicos e com o tempo, tempo, tempo... dos deuses mais lindos, como diria Caetano Veloso.

Já em plena era de Aquarius, seria bom avançar uma das máximas da era de Peixes: "Amar ao próximo como a si mesmo". Como diria meu amigo e mestre João Frayze-Pereira : "Quem disse isso acabou crucificado". Se nosso narciso não é capaz de amar quem não é espelho, como também diria o Caetano Veloso, na pressa de cuidar e proteger acabamos por crucificar também o outro, nos outros $e$ em nós mesmos.

Melhor amar ao próximo como ele é, onde ele está, aprendendo com ele. São Paulo, Primavera de 2001

\section{Referências}

AURÉLIO, B. H. F. Novo Dicionário da Língua Portuguesa. 15.ed. Rio de Janeiro: Nova Fronteira, s/d.

AYRES, J.R.; FRANÇA-JR. I.; CALAZANS, G.; SALETTI, F. H. Vulnerabilidade e prevenção em tempos de Aids. In: BARBOSA, R. M., PARKER, R. (Orgs.) Sexualidades pelo avesso. São Paulo: Editora 34, 2000. p.49-73.

AYRES, J. R. Sujeito, intersubjetividade e práticas de saúde. Ciênc. Saúde Coletiva, v.6, n.1, p. 63-73, 2001. BAPTISTELLA NEMES, M.I. Aderência ao tratamento por anti-retrovirais em serviços públicos de saúde no Estado de São Paulo. Brasília: Coordenação Nacional de DST e AIDS/ Ministério da Saúde, 2000. (Série Avaliação, n.1)

CEBRAP. MINISTÉRIO DA SAÚDE. Comportamento sexual da população brasileira e percepções sobre HIV e Aids. Versão Preliminar do Relatório de Pesquisa. jul.1999. Disponível em <www.aids.gov.br>. Acesso em abr. 2002.

ENHANCING CARE INITIATIVE. Mulheres e Aids: desafios para os serviços. Disponível em $<$ www.eci.harvard.edu>. Acesso em abr. 2002.

FREIRE, P. Pedagogia do oprimido. Rio de Janeiro: Paz e Terra, 1989.

INTERNATIONAL AIDS CONFERENCE, 13 Durban, 2000. Abstracts... Durban, 2000. CD-Room.

PAIVA, V. Sexualidades adolescentes: escolaridade, gênero e o sujeito sexual. In: PARKER, R. , BARBOSA, R. (Orgs.) Sexualidades brasileiras. Rio de Janeiro: Relume-Dumará, 1996. p.213-35.

PAIVA, V., BUGAMELLI, L., LEME, B., VENTURA-FILIPE, E., TUNALA, L., SANTOS, N. J. Sida, vulnerabilidad y condicionantes de género. In: GÓMEZ, A. (Ed.) Cuadernos Mujer Salud. 3.ed. Santiago: RSMLAC, 1998. p.34-9.

PAIVA, V. Fazendo arte com camisinha. São Paulo: Summus Editorial, 2000a. cap.1, p.25-54. 
PAIVA, V.

PAIVA, V. Cenas sexuais, roteiros de gênero e sujeito sexual. In: BARBOSA, R., PARKER, R. (Orgs.) Sexualidades pelo avesso. São Paulo: Editora 34, 2000b. p.248-69.

PAIVA, B., LEME, R., NIGRO, J., CARACIOLO, J. Lidando com adesão: a experiência de profissionais e ativistas na cidade de São Paulo. In: TEIXEIRA, P., PAIVA, V., SHIMMA, E. Tá difícil de engolir. São Paulo: CRT/ Nepaids, 2000c. p.28-79.

PAIVA, V., LATORRE, M.R., GRAVATO, N. , LACERDA, R. In: ECI-Brasil. Sexualidade das mulheres vivendo com HIV/AIDS em São Paulo. 2001. (mimeogr.)

PARKER , R. A construção da solidariedade - AIDS, sexualidade e política no Brasil. Rio de Janeiro: RELUME-DUMARÁ/IMS/ABIA, 1994.

PARKER, R. Na contramão da AIDS: sexualidade, intervenção, política. Rio de Janeiro: ABIA. São Paulo: Editora 34, 2000.

PASSARELLI, C. As patentes e os remédios contra a AIDS: uma cronologia. Boletim ABIA, n.46. , p.6-8, Julho/setembro, 2001.

ROTHERAM-BORUS, M.J., MILLER, S. Secondary prevention for youth living with HIV. Aids Care, v.10, n.1, p.17-34, 1998.

SANTOS, N., VENTURA-FILIPE, E., PAIVA, V. HIV-positive women, reproduction and sexuality in São Paulo, Brazil. Reprod. Health Matters, v.6, n.12, p.31-41, 1998.

SCHILTZ, M.A, SANDFORT, G.M. HIV-positive people, risk and sexual behavior. Soc. Sci. Med., n.50, p.1571-88, 2000.

TEIXEIRA, P. Políticas públicas em AIDS. Políticas, instituições e AIDS. In: PARKER, R. (Org.) Enfrentando a epidemia no Brasil. Rio de Janeiro: ABIA/ Jorge Zahar Editor, 1997. p.43-69.

TEIXEIRA, P.; PAIVA, V.; SHIMMA, E. Tá difícil de engolir. São Paulo: CRT/NEPAIDS, 2000.

TUNALA, L., PAIVA, V., VENTURA-FELIPE, E., SANTOS, T., SANTOS, N., HEARST, N. Fatores

psicossociais que dificultam a adesão das mulheres portadoras do HIV aos cuidados de saúde. In: TEIXEIRA, P., PAIVA, V., SHIMMA, E. (Orgs.) Tá difícil de engolir. São Paulo: CRT/NEPAIDS, 2000. p.108.

UNAIDS. Impacto de la educación en materia de salud sexual y VIH sobre el comportamiento sexual de los jóvenes: actualizacion de un análisis. Genebra: UNAIDS, 1997.

UNAIDS. Gender and HIV/AIDS: taking stock of research and programs. Geneva: UNAIDS, 1999.

PAIVA, V. Sin soluciones mágicas: prevención y cuidado en VIH/SIDA y la emancipación sicosocial, Interface - Comunic, Saúde, Educ, v.6, n.11, p.25-38, 2002.

Este texto discute la necesidad de politizar los espacios sico-educativos y propone la noción de "emancipación sico-social" como una de las referencias para discutir más profundamente la operacionalización de la noción de vulnerabilidad en el campo de la prevención de nuevas infecciones por el VIH y de la organización del cuidado de los portadores. Reflexionando sobre acciones para la adhesión al preservativo y a los medicamentos, sugiere que la prevención debe superar su modelo pensado, en general, para ciudadanos "VIH negativos" y que se radicalice el continuo prevenir-asistir. Para esto, es urgente considerar los hechos acumulados en la investigación socio-cultural y sico-social en el planeamiento y organización de acciones de prevención y asistencia a los portadores incorporando, por ejemplo, las nociones de la construcción social opresiva de dos géneros, masculino y femenino. Superar la noción de "individuo-consumidor" (de servicios, programas educativos, preservativos y medicamentos recetados, de comportamientos y prácticas seguras que necesitan entrenamiento) estimulando la renovación de las acciones de prevención y cuidado. Trabajar con la noción de "individuosujeto- ciudadano", participante de espacios sico-educativos que tienen en el horizonte la emancipación sico-social, puede renovar las acciones de prevención y cuidado integral en VIH y SIDA, incluyendo "todos" los brasileños según el contexto socio-cultural de "cada uno", hombres y mujeres, positivos y negativos.

PALABRAS CLAVE: VIH; Síndrome de inmunodeficiencia adquirida; apoyo social; educación en salud.

Recebido para publicação em: 13/12/01. Aprovado para publicação em: 29/05/02 